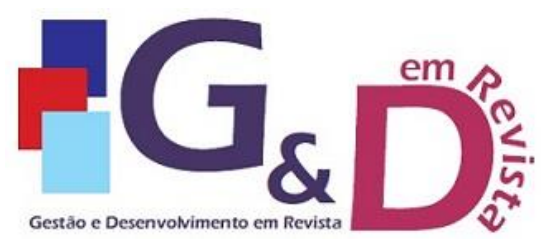

Gestão e Desenvolvimento em Revista

V. 7, N. 1, jan-jun/2021, p. 82-99.

ISSN online: $2446-8738$

Artigo recebido em: 05/06/2021

Artigo aprovado em: 16/08/2021

\title{
GESTÃO ESTRATÉGICA PARA COMPRAS: UMA REVISÃO BIBLIOGRÁFICA DA LITERATURA NACIONAL
}

\author{
Lucas Matheus Fonseca Bastos \\ Graduado em Engenharia de Produção pelo Centro Universitário Salesiano - UniSales. \\ E-mail: Imatheus01@gmail.com \\ Marcos Wagner Jesus Servare Junior \\ Mestre em Engenharia Civil pela Universidade Federal do Espírito Santo - UFES. Atualmente é \\ Doutorando em Engenharia Elétrica pela Universidade Federal do Espírito Santo - UFES. \\ E-mail: marcos.servare@salesiano.br
}

\begin{abstract}
Resumo
Diante das dificuldades comerciais vividas entre atacadistas na disputa por preços, parcerias e confiança, para empresas que buscam se destacar é necessário iniciar um trabalho de organização setorial e explorar possibilidades da aplicação de um diferencial competitivo para se sobressair entre os concorrentes diretos. Desta forma, tendo uma boa gestão estratégica a empresa consegue se estabelecer podendo ser assertivo nas tomadas de decisão, seleção de fornecedores e adequação na aquisição de suprimentos. A partir disso, esse estudo tem como objetivo de propor uma revisão sistemática da literatura a partir da análise sistêmica e bibliográfica das obras nacionais levantadas, selecionando uma base de artigos que poderá servir como pilar estrutural para novas análises e direcionamentos neste campo. Assim realizando uma revisão de literatura e análise bibliográfica de artigos já publicados, disponibilizando um portfólio bibliográfico a respeito do tema proposto e para isso, foi utilizada a metodologia ProKnow-C desenvolvida pelo Laboratório MCDA da Universidade Federal de Santa Catarina, que possibilita pesquisar e analisar quantitativamente artigos científicos com relevância na temática, evidenciando autores, periódicos, eixo de pesquisas e palavras-chave diretamente relacionadas ao objetivo, sendo importante para pesquisadores da área.
\end{abstract}

Palavras-chave: Compras, gestão estratégica, planejamento estratégico, análise de estoque, previsão de demanda.

\begin{abstract}
Given the commercial difficulties experienced between wholesalers in the dispute for prices, partnerships and trust, for companies seeking to stand out, it is necessary to start a sectorial organization work and explore possibilities of applying a competitive differential to stand out among direct competitors. In this way, with good strategic management, the company is able to establish itself and can be assertive in decision-making, supplier selection and adequacy in the acquisition of supplies. From this, this study aims to propose a systematic review of the literature from the systemic and bibliographic analysis of national works surveyed, selecting a base of articles that can serve as a structural pillar for new analyzes and directions in this field. Thus performing a literature review and bibliographic analysis of articles already published, providing a bibliographic portfolio about the proposed theme and for this, the ProKnow-C methodology developed by the MCDA Laboratory of the Federal University of Santa Catarina was used, which enables research and analysis quantitatively scientific articles relevant to the subject, highlighting authors, journals, research axis and keywords directly related to the objective, being important for researchers in the field.
\end{abstract}

Keywords: Purchasing, strategic management, strategic planning, inventory analysis, demand forecast. 


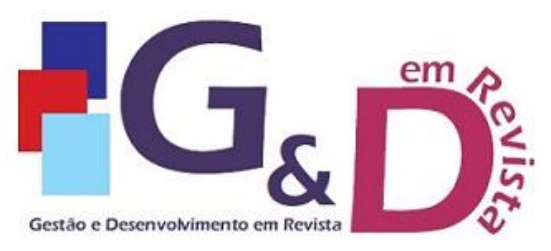

Gestão e Desenvolvimento em Revista V. 7, N. 1, jan-jun/2021, p. 82-99.

ISSN online: $2446-8738$

Artigo recebido em: 05/06/2021

Artigo aprovado em: 16/08/2021

\section{INTRODUÇÃO}

No cenário atual a busca por destaque, vantagens competitivas e melhoria contínua vêm crescendo com grande intensidade, visto que esta competitividade cada vez mais acentuada acaba gerando conflitos no mercado de atacadistas, entre as empresas em geral existe uma procura por diferenciação sob a concorrência em termos de flexibilidade, inovação e um padrão de serviços com maior qualidade.

Desta forma para se destacar no mercado a empresa deve se organizar no quesito tomada de decisão, que faz parte da rotina empresarial na gestão estratégica do setor de compras. O encargo fundamental de compras em uma organização é garantir que a aquisição dos itens seja realizada corretamente, na quantidade adequada, com o menor preço, seguindo padrões de negociação e garantindo qualidade no serviço prestado (SLACK et al, 1999).

A gestão estratégica no setor de compras é adotada por várias empresas com objetivo de se obter excelência na aquisição de produtos, serviços prestados e seleção adequada de fornecedores, considerando sempre uma boa negociação. Esta seleção adequada de fornecedores tem grande importância entre as organizações, afinal através da utilização de estratégias bem definidas em acordos comerciais pode se obter melhores resultados e vantagens competitivas, além de aumento da eficiência, redução dos custos, rapidez na entrega e melhor preço no mercado, assim se destacando, aumentando o desempenho organizacional.

Esta gestão com estratégias predefinidas e aplicadas corretamente também se torna muito eficaz na redução de faltas e rupturas de estoque, garantindo que o atacadista sempre tenha produtos a disposição para rápida reposição dos lojistas quando solicitado, sendo assim um diferencial competitivo dentre os concorrentes.

Mediante a dificuldade de atuação no setor este artigo tem como objetivo propor uma revisão sistemática da literatura a partir da análise sistêmica e bibliográfica das obras nacionais levantadas, referente aos periódicos Gestão e Desenvolvimento em Revista, Revista Produção Online, juntamente aos congressos ENEGEP e SIMPEP a partir de 2015, utilizando a metodologia ProKnow-C, assim selecionando uma base de artigos que poderá servir como fundamento e pilar para novas análises e direcionamentos voltados ao desenvolvimento do setor de compras. 
Desta forma, sendo classificado no ponto de vista pela sua natureza a Pesquisa Aplicada pois gera conhecimento e se necessário poderá ser aplicada de forma prática. No ponto de vista de abordagem do problema a Pesquisa Quantitativa considerando tudo que possa ser quantificável, opiniões e informações, classificando e analisando. No ponto de vista de objetivos a Pesquisa Exploratória pois visa proporcionar maior familiaridade com o problema a partir de pesquisas bibliográficas e análises. No ponto de vista de procedimentos técnicos a Pesquisa bibliográfica, sendo elaborada a partir de materiais publicados, enfatizando artigos de periódicos.

Esse trabalho é divido em Seções, onde a Seção 1 introduz o assunto e apresenta o contexto geral desta pesquisa, na Seção 2 é apresentado o referencial teórico dos temas importantes para o desenvolvimento desta pesquisa. Por sua vez, a Seção 3 apresenta a utilização do ProKnow-C para obtenção do portfólio bibliográfico, análise bibliométrica e análise sistêmica, seguidos pelas considerações finais na Seção 4 e, por fim, as referências utilizadas.

\section{REFERENCIAL TEÓRICO}

A gestão de compras afeta diretamente nos objetivos e capacidades das organizações, com isso, é necessário que os líderes exerçam um bom gerenciamento no setor, pois essa gestão está assumindo cada vez mais o papel estratégico e decisivo nas empresas, pelo fato de ter relacionamento direto com os resultados financeiros (TELLES; LEAL, 2019).

O setor de compras exerce responsabilidades em alto nível, existindo uma crescente importância por conta do reconhecimento no volume de gastos direcionados a aquisição de suprimentos na empresa, exigindo ao processo um entendimento e direcionamento correto na abordagem estratégica da atividade (BOWERSOX, 2006).

Para se exercer com eficiência a tarefa de compras, deve-se planejar e definir os processos que serão executados. Segundo Chiavenato (2004), "planejamento é a função administrativa que definem objetivos e decide sobre os recursos e tarefas necessárias para alcançá-los adequadamente". Tendo em mãos os processos e tarefas definidas, o setor deverá seguir rigorosamente o determinado para que tenha êxito na atividade. 
As aquisições realizadas devem ser moldadas e direcionadas a partir de um estoque máximo e mínimo delimitado pelas demandas existentes. De acordo com Lustosa et al. (2008), "demanda é a disposição dos clientes ao consumo de determinados bens ou serviços de uma organização". Sendo assim, o comprador deve analisar os níveis de estoque e evitar ao máximo os pontos de faltas e rupturas, tendo sempre disponibilidade para atender as solicitações imediatas. Existem dois cenários que devem ser evitados: estoque em excesso, tendo assim duração em longo prazo ou estoque insuficiente e em atraso, gerando perdas, insatisfação e menor produtividade (CHIAVENATO, 2005).

A escolha de fornecedores, é um processo rigoroso e deve ser analisado detalhadamente para que seja feita uma boa seleção do parceiro distribuidor, existem critérios para seleção deles, de acordo com Baily et al. (2000, p. 352) "Os critérios padronizados para a seleção de fornecedor são: qualidade, preço, condições, entrega e serviço, acompanhados do desempenho real no atendimento de pedidos anteriores". Tendo como objetivo principal nesta avaliação, conseguir a comprovação de que o fornecedor selecionado tenha disponibilidade e capacidade para atender os requisitos específicos quando solicitado, garantindo prazo e qualidade acordado entre as partes interessadas (GURGEL; FRANCISCHINI, 2002, p. 62).

\section{PROKNOW-C.}

Este trabalho foi baseado na análise e estudo de artigos já publicados, evidenciando quantitativamente o conjunto de artigos obtidos, sendo muito importante a análise realizada e a apreciação dos dados levantados. Desta forma, foi utilizado a técnica ProKnow-C, sendo uma ferramenta de seleção e inspeção de artigos, auxiliando na compreensão do tema sob um agrupamento de artigos identificados, assim, proporcionando um reconhecimento do que já foi publicado referente ao tema e no gerenciamento e acepção da revisão de literatura desenvolvida.

\subsection{SELEÇÃO DO PORTFÓLIO BIBLIOGRÁFICO}

\subsubsection{Seleção do banco de artigos brutos}


$\mathrm{Na}$ procura de publicações expressivas sobre o tema "Os impactos da implantação da gestão estratégica no setor de compras de um atacado de materiais para construção no Espírito Santo", foram selecionados artigos da literatura mundial e preferencialmente artigos da literatura nacional publicados em revistas e congressos direcionados a área, definindo-os como base de pesquisa para coleta de dados. Progredindo assim as seguintes etapas:

- Determinar Eixos de Pesquisa e Palavras-Chave: Tendo como base uma leitura inicial de artigos e projetos de pesquisa relacionados ao tema, foram selecionados artigos que enfatizassem a situação principal dentro dos parâmetros do eixo definido e com isso foi realizada a definição das palavras-chave. Sendo elas:

Tabela 1. Eixo de Pesquisa e Palavras-chave EIXO: GESTÃO DE SUPRIMENTOS

\begin{tabular}{c}
\hline Compras \\
\hline Planejamento estratégico \\
\hline Análise de estoque \\
\hline Previsão de demanda \\
\hline
\end{tabular}

- Definir Banco de Dados: Foram determinados como Banco de Dados: SIMPEP, ENEGEP, Gestão e Desenvolvimento em Revista, Revista Produção Online. Tendo esses como fontes com grande qualificação e disponibilidade de artigos de qualidade e propriedades para seleção e das bases de maior aderência com o assunto da pesquisa.

- Busca de artigos: Realizar a busca de artigos que contenham as palavras-chave determinadas no primeiro momento em seus títulos, resumos e palavras-chaves ou que fossem correlacionadas e semelhantes. Esta busca foi traçada pelo ano de produção e publicação dos artigos tais entre 2015 e 2021, com isso, o resultado desta etapa, tendo 1 eixo e 4 PCs determinadas, possibilitou na seleção de 1.402 artigos brutos cientificamente reconhecidos, conforme apresentado na Figura 1. 


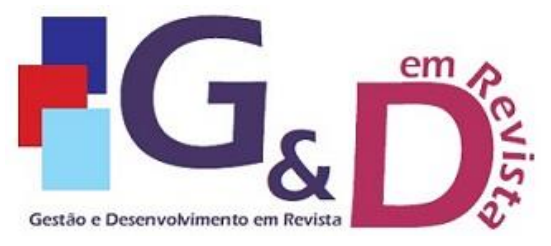

Gestão e Desenvolvimento em Revista V. 7, N. 1, jan-jun/2021, p. 82-99.

ISSN online: $2446-8738$

Artigo recebido em: 05/06/2021

Artigo aprovado em: 16/08/2021

Figura 1. Artigos por periódico na Busca de Artigos

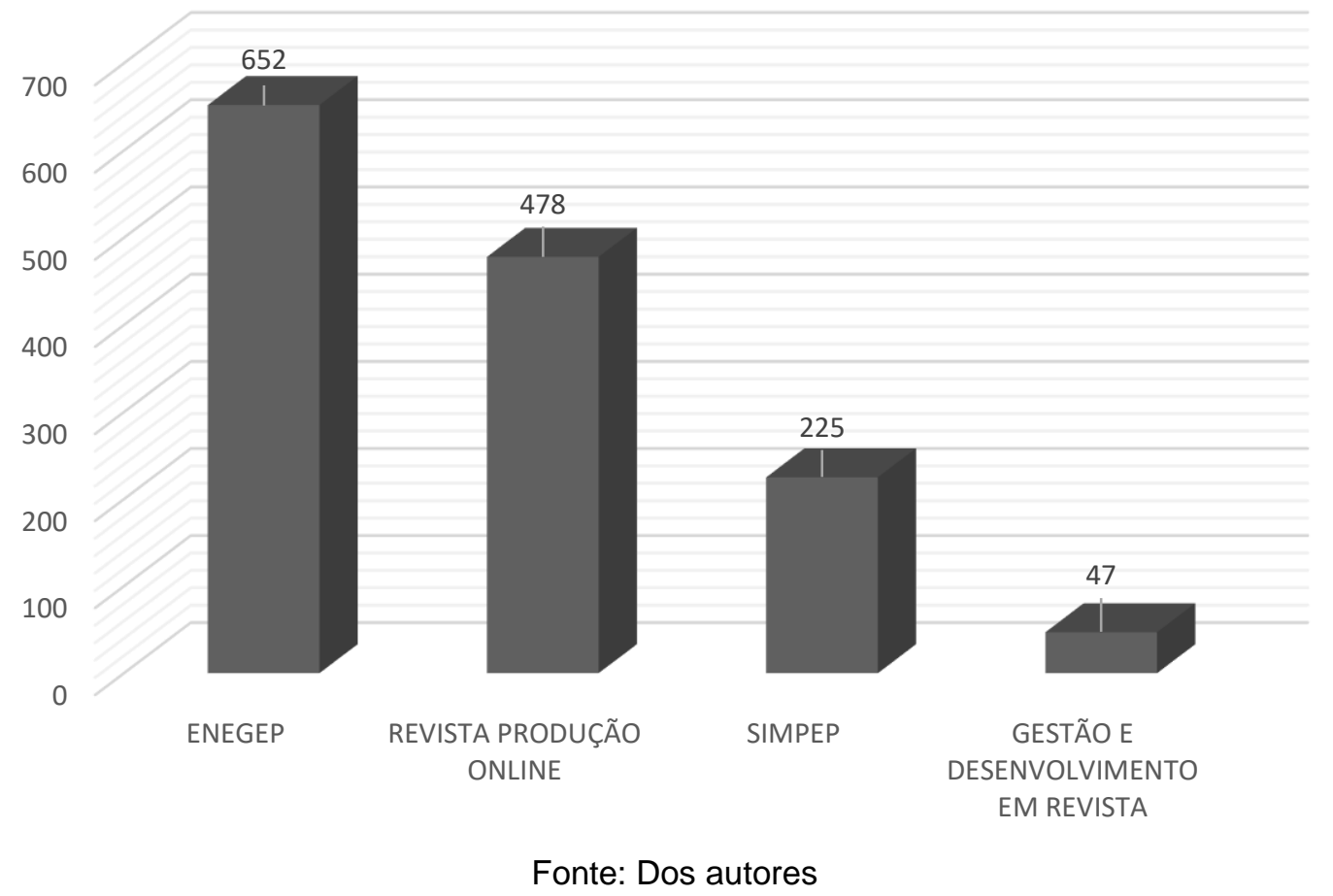

- Teste de aderência das palavras-chave: Nesta etapa é necessário verificar se as palavras-chave pré-selecionadas realmente são as melhores para realizar pesquisas dos artigos voltados ao tema determinado. Com isso é indicado na metodológica ProKnow-C a seleção de dois artigos dentre os selecionados nos anais para o banco de artigos brutos para se realizar uma verificação dentre as palavras-chave destes artigos a existência da aderência e alinhamento com as que já foram selecionadas.

\subsubsection{Filtragem do banco de artigos brutos}

A etapa de filtragem do branco de artigos brutos (BAB) constitui-se da seleção de artigos que tenha alto nível de relação com o tema de pesquisa proposto e que possua relevância significativa. Assim sendo listados os filtros que o BAB será submetido buscando os principais artigos para originar a carteira bibliográfica.

- Filtro do BAB quanto à Redundância: inicialmente, neste filtro é realizada a listagem de todos os artigos selecionados com auxílio de planilhas no Excel, possibilitando a organização e aplicação de técnicas para a filtragem, que se dá por realizar a exclusão em virtude de todos os artigos que acidentalmente estejam repetidos e presentes no Bando de dados. Com isso, nessa etapa foi identificado que (345) $24,61 \%$ dos artigos se repetiam, sendo removidos. Dessa forma, o Banco de Artigos Brutos passou de 1.402, para 1.057 artigos não iterados. 
- Filtro do BAB não repetidos quanto ao Alinhamento dos Títulos: nessa etapa de filtragem são analisados detalhadamente os títulos dos 1.057 artigos não repetidos, verificando a ligação direta de seus títulos com o tema e eixo determinados na fase inicial. Assim, artigos que possuem relação com o proposto, permanecem no banco. Já artigos sem correlação e alinhamento são excluídos. Com a aplicação do filtro, foram removidos 990 artigos que não continham relação com o tema. Portanto, no Banco de Artigos Brutos permaneceram 67 artigos, apenas $6,34 \%$ do total.

- Filtro do BAB quanto ao Reconhecimento Científico: prosseguindo as técnicas da metodologia ProKnow-C, nesse filtro é necessário realizar uma busca do número de citações que cada artigo do banco possui. Assim, com auxílio das ferramentas disponibilizadas no Google Acadêmico que mostra quantas vezes os selecionados obtiveram citações em demais projetos, podem-se listar separadamente os destaques. Sendo observado que a minoria dos artigos selecionados possuía citações, foram classificados de forma decrescente e realizado uma somatória de percentual acumulado perante a $90 \%$ de representatividade dos artigos, que consequentemente corresponde a todos os artigos com citações. Após esta apuração, foram analisados os artigos com datas de publicação entre 2020 e 2021 e mantidos por serem considerados recentes e talvez, por esta condição ainda não tenha recebido citações. Em seguida foi realizada a leitura dos resumos, examinando os mesmos podendo ser observado se os artigos restantes possuem alinhamento com o tema proposto e a total disponibilidade sendo isento de taxas e filiações para fins de estudo. Desta forma, restaram 21 artigos para o desenvolvimento de análise bibliométrica.

- Filtro quanto ao Alinhamento do Artigo Integral: essa etapa final de aplicação dos filtros consiste em realizar a leitura completa dos artigos, buscando verificar se todos os restantes estão adequadamente alinhados com o proposto, finalizando este estudo foi identificado 1 artigo não elegível. Com isso, permaneceram 20 artigos relevantes e coerentes para análise específica.

A evolução do desenvolvimento da metodologia, com a redução da quantidade de trabalhos no banco de artigos até a formação do Portfólio Bibliográfico, pode ser observada na Figura 2. 


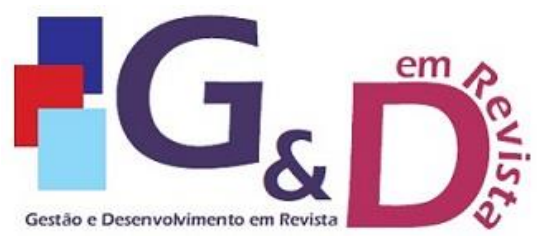

Gestão e Desenvolvimento em Revista V. 7, N. 1, jan-jun/2021, p. 82-99.

ISSN online: $2446-8738$

Artigo recebido em: 05/06/2021

Artigo aprovado em: 16/08/2021

Figura 2. Gráfico demonstrativo da seleção de artigos seguindo a metodologia "ProKnow-C"

\section{Quantidade de artigos por etapa de seleção}

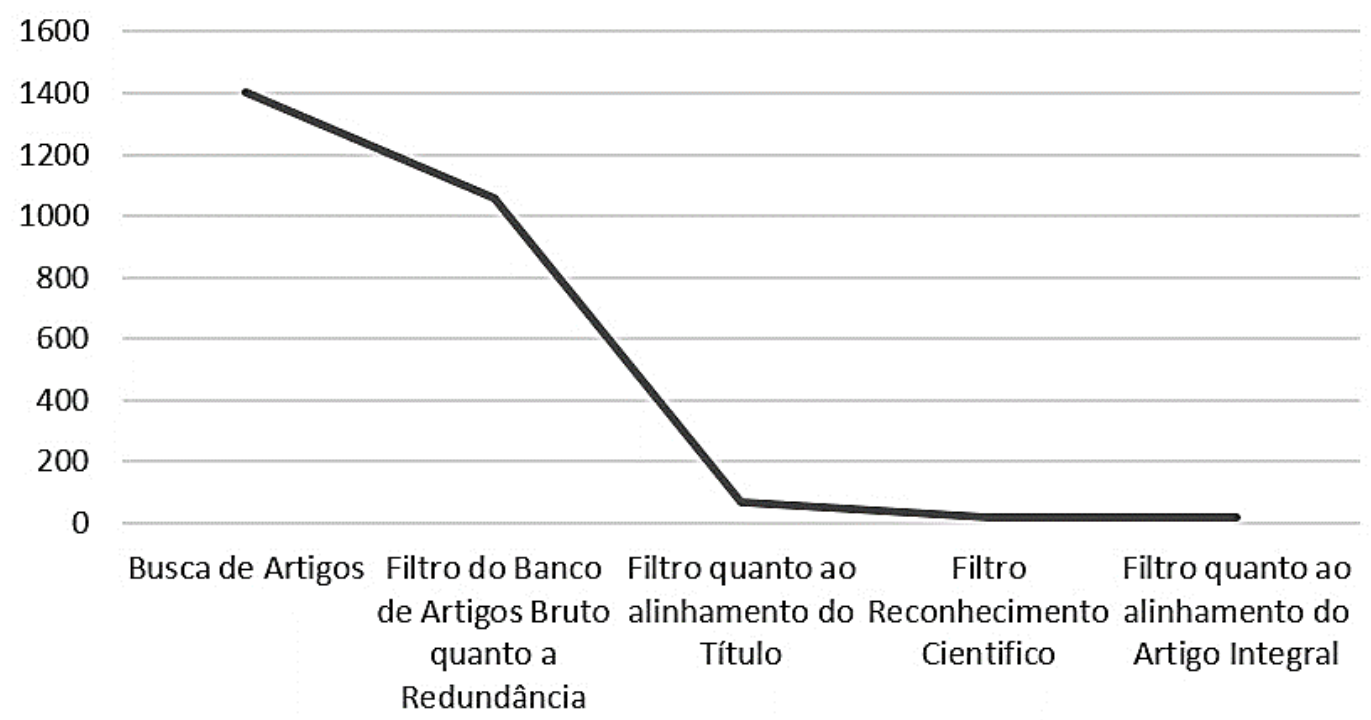

Fonte: Dos autores

Após o filtro de leitura completa dos artigos, $\mathrm{Na}$ Tabela 2 é possível observar informações referentes aos artigos mais relevantes que compõem o banco de artigos para realização de análises bibliométricas.

Tabela 2. Portfólio bibliográfico sobre Os impactos da implantação da gestão estratégica no setor de compras de um atacado de materiais para construção no espírito santo.

\begin{tabular}{|c|c|c|c|c|c|}
\hline$\#$ & Título & Autores & Periódicos & Ano & Citações \\
\hline 1 & $\begin{array}{c}\text { Aplicação do sistema máximo- } \\
\text { mínimo no controle de estoque } \\
\text { de uma empresa do segmento } \\
\text { termoplástico }\end{array}$ & $\begin{array}{c}\text { Jeanderson Caique Ribeiro Borba, } \\
\text { Jorge Vieira Mesquita, Moises } \\
\text { Alexandre De Melo Santos, Thaina } \\
\text { Tamiris De Souza, Fabio De Brito } \\
\text { Gontijo }\end{array}$ & ENEGEP & 2015 & 7 \\
\hline 2 & $\begin{array}{l}\text { Aplicação de técnicas de } \\
\text { previsão de demanda em uma } \\
\text { loja de materiais de construção }\end{array}$ & $\begin{array}{c}\text { Fernanda Quiteria Arraes Pimentel, } \\
\text { Roberta Guedes Guilhon Cruz, } \\
\text { Rafael Pereira Guerreiro }\end{array}$ & ENEGEP & 2016 & 3 \\
\hline 3 & $\begin{array}{l}\text { Métodos quantitativos para } \\
\text { seleção de fornecedores } \\
\text { sustentáveis: uma revisão } \\
\text { sistemática da literatura }\end{array}$ & $\begin{array}{c}\text { Gilberto Miller Devós Ganga, } \\
\text { Letícia Reis Rodrigues, Rui } \\
\text { Tadashi Yoshino, Luis Antonio de } \\
\text { Santa-Eulalia }\end{array}$ & $\begin{array}{l}\text { Revista } \\
\text { Produção } \\
\text { Online }\end{array}$ & 2016 & 3 \\
\hline 4 & $\begin{array}{l}\text { Iniciativas de desenvolvimento } \\
\text { de fornecedores: estudo de } \\
\text { caso em uma indústria de } \\
\text { equipamentos de limpeza }\end{array}$ & $\begin{array}{c}\text { Bonato, S. V., Isoppo, A. S., } \\
\text { Santos, C., Pereira Junior, E. F. Z. }\end{array}$ & SIMPEP & 2019 & 2 \\
\hline 5 & $\begin{array}{l}\text { Os reflexos da análise da curva } \\
\text { abc na gestão de estoques de } \\
\text { uma empresa comercial de } \\
\text { materiais de construção }\end{array}$ & $\begin{array}{c}\text { Lais Milanez Ronchi, Leopoldo } \\
\text { Pedro Guimaraes Filho, Milla Lucia } \\
\text { Ferreira Guimaraes, Andreia } \\
\text { Cittadin }\end{array}$ & ENEGEP & 2016 & 2 \\
\hline
\end{tabular}




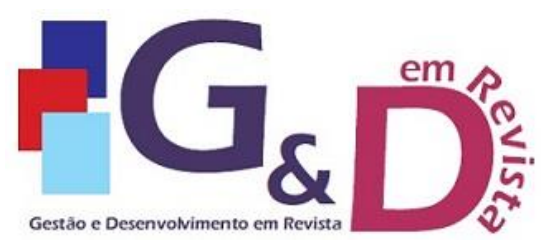

Gestão e Desenvolvimento em Revista

V. 7, N. 1, jan-jun/2021, p. 82-99.

ISSN online: $2446-8738$

Artigo recebido em: 05/06/2021

Artigo aprovado em: 16/08/2021

\begin{tabular}{|c|c|c|c|c|c|}
\hline 6 & $\begin{array}{l}\text { Planejamento estratégico no } \\
\text { setor público: análise das } \\
\text { variáveis que influenciam o } \\
\text { processo de compras em uma } \\
\text { instituição de ensino } \\
\end{array}$ & $\begin{array}{c}\text { Jane Inacio De Andrade, Robert } \\
\text { Cruzoaldo Maria }\end{array}$ & ENEGEP & 2015 & 2 \\
\hline 7 & $\begin{array}{c}\text { Programação de suprimentos e } \\
\text { decisões de compras: o } \\
\text { impacto em uma indústria } \\
\text { salineira } \\
\end{array}$ & $\begin{array}{c}\text { Ana Clara Cachina Saraiva, Jose } \\
\text { Raeudo Pereira, Juliana Araujo De } \\
\text { Sousa. }\end{array}$ & ENEGEP & 2015 & 2 \\
\hline 8 & $\begin{array}{l}\text { Aplicação das ferramentas da } \\
\text { qualidade no setor de compras } \\
\text { visando redução de custos }\end{array}$ & $\begin{array}{l}\text { Guilherme Bulhões Carvalho, } \\
\text { Nelson Aparecido Alves. }\end{array}$ & ENEGEP & 2020 & 0 \\
\hline 9 & \begin{tabular}{|c|} 
Estratégias no setor de \\
compras que influenciam a \\
performance das aquisições de \\
materiais indiretos em uma \\
empresa alimentícia \\
\end{tabular} & $\begin{array}{l}\text { Lucas Maia Ximenes Aragão, } \\
\text { Thiago Costa Holanda, Natália } \\
\text { Varela Da Rocha Kloeckner }\end{array}$ & ENEGEP & 2020 & 0 \\
\hline 10 & $\begin{array}{c}\text { Estudo comparativo entre } \\
\text { modelos de previsão de } \\
\text { demanda em uma empresa de } \\
\text { pronta entrega }\end{array}$ & $\begin{array}{c}\text { Danylo De Araujo Viana, Vinícius } \\
\text { José Silva De Oliveira, Hermerson } \\
\text { Teixeira Dias Da Silva, Matheus } \\
\text { Bezerra Maia De Hollanda } \\
\text { Simonetti De Carv, Víctor Matheus } \\
\text { Silva Araújo. }\end{array}$ & ENEGEP & 2020 & 0 \\
\hline 11 & $\begin{array}{c}\text { Gestão de relacionamento com } \\
\text { fornecedores em uma empresa } \\
\text { do setor de bens de consumo: } \\
\text { um estudo de caso }\end{array}$ & $\begin{array}{l}\text { Augusto Alves Batalha, Renato Da } \\
\text { Silva Lima. }\end{array}$ & ENEGEP & 2020 & 0 \\
\hline 12 & $\begin{array}{c}\text { Gestão dos fornecedores de } \\
\text { embalagens e uma empresa de } \\
\text { cosméticos }\end{array}$ & $\begin{array}{c}\text { Vítor Meirelles Dos Reis Almeida, } \\
\text { Priscilla Cristina Cabral Ribeiro, } \\
\text { Helder Gomes Costa, Carlos } \\
\text { Francisco Simões Gomes. }\end{array}$ & ENEGEP & 2020 & 0 \\
\hline 13 & $\begin{array}{c}\text { O uso da curva abc para } \\
\text { gestão de estoques e } \\
\text { fornecedores: uma aplicação } \\
\text { em uma indústria de } \\
\text { compressores do interior de } \\
\text { São Paulo }\end{array}$ & $\begin{array}{c}\text { Renan Milhorini Merces, Bruna } \\
\text { Cristine Scarduelli Pacheco, Layris } \\
\text { Menezes De Oliveira. }\end{array}$ & ENEGEP & 2020 & 0 \\
\hline 14 & $\begin{array}{c}\text { Proposta de aplicação da teoria } \\
\text { da utilidade para tomada de } \\
\text { decisão: escolha do modal de } \\
\text { importação em um processo de } \\
\text { compras numa empresa do } \\
\text { setor tecnológico } \\
\end{array}$ & $\begin{array}{c}\text { Luiz Carlos Fernandes De Lima, } \\
\text { Sandro Toledo, Ronan Wendell De } \\
\text { Oliveira E Silva, Fábio Favaretto, } \\
\text { Fabiano Leal. }\end{array}$ & ENEGEP & 2020 & 0 \\
\hline 15 & $\begin{array}{c}\text { Proposta de metodologia para } \\
\text { avaliação e seleção de } \\
\text { fornecedores em uma indústria } \\
\text { madeireira: uma abordagem } \\
\text { baseada em análise hierárquica } \\
\text { de processos }\end{array}$ & $\begin{array}{l}\text { Rodrigo Rangel Ribeiro Bezerra, } \\
\text { Breno Guilherme Dos Reis } \\
\text { Mendes, André Cristiano Silva } \\
\text { Melo, Gilson Silva Castro. }\end{array}$ & ENEGEP & 2020 & 0 \\
\hline 16 & $\begin{array}{c}\text { Aplicação do método de } \\
\text { previsão de demanda holt- } \\
\text { winters para uma empresa de } \\
\text { bebidas }\end{array}$ & $\begin{array}{c}\text { Tharine Da Silva Santos, Liane } \\
\text { Márcia Freitas E Silva. }\end{array}$ & ENEGEP & 2020 & 0 \\
\hline 17 & $\begin{array}{c}\text { Gestão de estoque com a } \\
\text { implantação do sistema MRP } \\
\text { (planejamento de requerimento } \\
\text { de materiais) em uma indústria } \\
\text { de reatores } \\
\end{array}$ & $\begin{array}{l}\text { Mariela Fioravanti Da Silva, } \\
\text { Fabiane Fidelis Querino, Rafaela } \\
\text { Da Silva Gomes, Fernanda } \\
\text { Teixeira Franco Ribeiro, Leandro } \\
\text { Lima Resende. }\end{array}$ & ENEGEP & 2020 & 0 \\
\hline 18 & $\begin{array}{c}\text { Cálculo e comparação de } \\
\text { modelos de previsão de } \\
\text { demanda de uma fabricante de } \\
\text { componentes plásticos }\end{array}$ & $\begin{array}{c}\text { Nathalia Tessari Moraes, Rodrigo } \\
\text { Biasuz, Bruna Caroline Orlandin, } \\
\text { Wander Carlos Bortolon, Leandro } \\
\text { Luis Corso. }\end{array}$ & ENEGEP & 2020 & 0 \\
\hline
\end{tabular}




\begin{tabular}{c|c|c|c|c|c}
\hline $\mathbf{1 9}$ & $\begin{array}{c}\text { A importância das compras de } \\
\text { indiretos e suas estratégias em } \\
\text { uma empresa de bens de } \\
\text { consumo }\end{array}$ & $\begin{array}{c}\text { Machado, S. L., Guimarães, M. R. } \\
\text { N., Lara, F. F. }\end{array}$ & SIMPEP & 2020 & 0 \\
\hline $\mathbf{2 0}$ & $\begin{array}{c}\text { Priorização de tipos de compra } \\
\text { por critérios comerciais e } \\
\text { aplicação de AHP }\end{array}$ & $\begin{array}{c}\text { Esteves, R. F. G., Hernández, C. } \\
\text { T., Costa, K. A., Christo, E. S. }\end{array}$ & SIMPEP & 2020 & 0 \\
\hline
\end{tabular}

Fonte: Dos autores

Referente a seleção dos 20 artigos listados no portfólio, possibilita a realização de uma análise bibliográfica quantitativa considerável de acordo com a origem das apurações a serem visualizadas, com base nos dados numéricos e informativos dos artigos, sendo representados nas figuras 3, 4, 5 e 6 .

Figura 3. Análise final com o número de citações por artigo

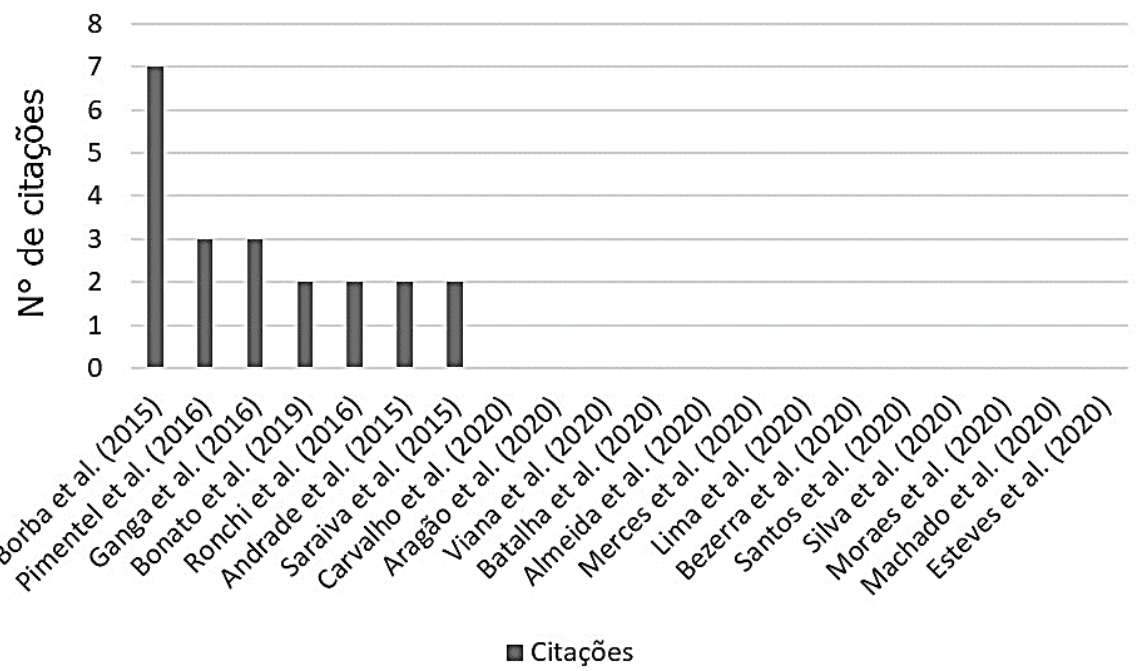

Fonte: Dos autores

Analisando quanto ao número de citações, percebe-se que dos 20 artigos existentes, apenas 7 possuem citações (35\%), quantidade referente a $90 \%$ da somatória do percentual acumulado, sendo assim, o restante dos artigos sem citações são justamente os que foram selecionados por serem recentes e que nessas condições ainda não tenham recebido citações. Quanto a quantidade de artigos selecionados por periódicos, é notado que $80 \%$ dos artigos do portfólio foram selecionados no congresso eletrônico ENEGEP e os outros $20 \%$ foram selecionados dos demais anais eletrônicos, observado na Figura 4. 


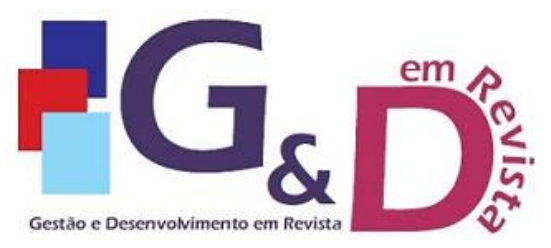

Gestão e Desenvolvimento em Revista V. 7, N. 1, jan-jun/2021, p. 82-99.

ISSN online: $2446-8738$

Artigo recebido em: 05/06/2021

Artigo aprovado em: 16/08/2021

Figura 4. Análise final com a quantidade de artigos por local de publicação

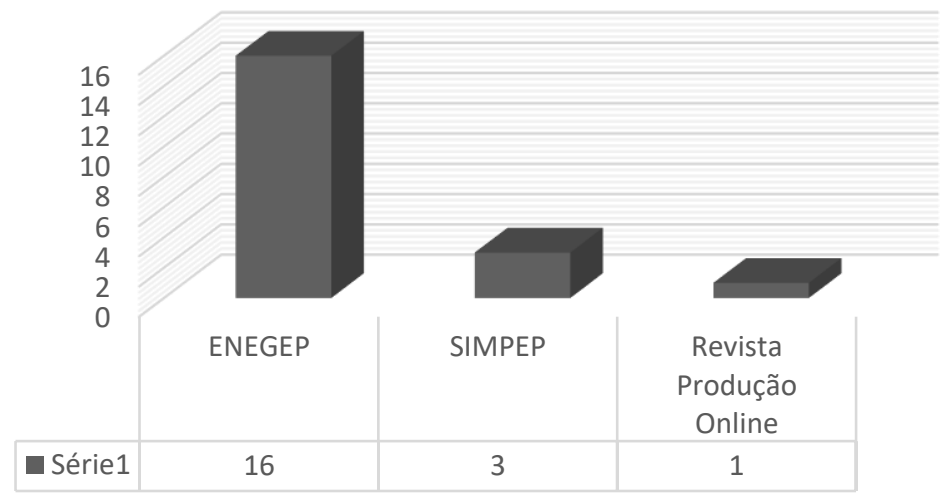

Fonte: Dos autores

\subsection{ANÁLISE BIBLIOMÉTRICA DO PORTFÓLIO BIBLIOGRÁFICO}

Com base na seleção do banco de artigos e com os filtros aplicados utilizando a metodologia ProKnow-C, foi possível notar nessa proposta de pesquisa voltada ao busca de artigos que estejam paralelamente interligados ao tema definido, que os artigos selecionados foram publicados entre 2015 à 2020, considerando que grande parte dentre os selecionados se localizam em 2020, pelo fato que o filtro referente ao reconhecimento científico indica que deve-se manter e preservar os artigos com publicações recentes, apesar de que o mesmo provavelmente não possua citações. Relação que pode ser observada nas Figuras 5 e 6.

Figura 5. Análise final com a quantidade de artigos por ano de publicação

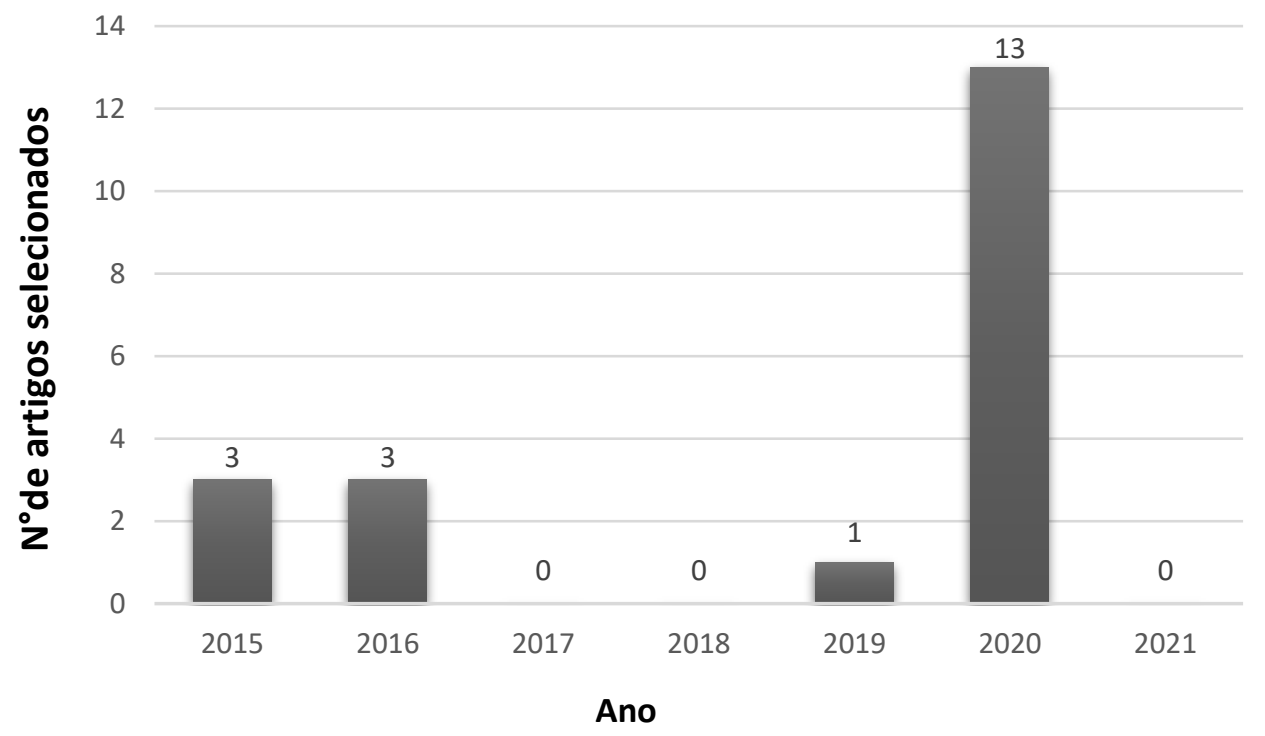

Fonte: Dos autores 


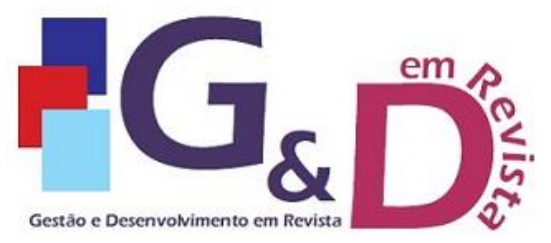

Gestão e Desenvolvimento em Revista V. 7, N. 1, jan-jun/2021, p. 82-99.

ISSN online: $2446-8738$

Artigo recebido em: 05/06/2021

Artigo aprovado em: 16/08/2021

Figura 6 Linha do tempo referente a quantidade de artigos por ano de publicação

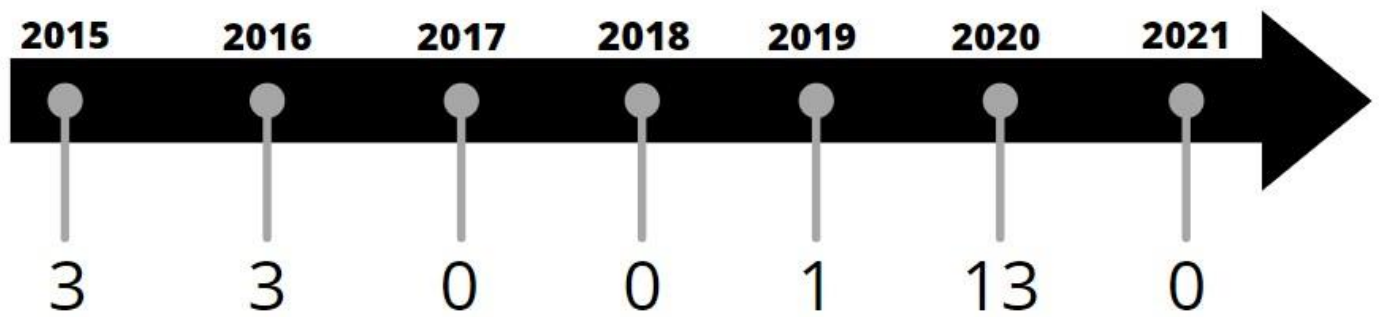

Fonte: Dos autores

Considerando que o maior volume de artigos se localiza em 2020, pode se afirmar que a busca e interesse por aperfeiçoamento do setor de compras e a melhoria contínua no planejamento estratégico nas organizações vem crescendo gradativamente, dando destaque a necessidade do planejamento e controle em todas as etapas percorridas buscando aperfeiçoar as aquisições e níveis de estoque e assim a produtividade. Também possibilita visualizar que grande parte das publicações referente ao tema pré-definido se encontra em congressos, aumentando a visibilidade e flexibilização dos meios de consulta e pesquisas on-line.

\subsection{ANÁLISE SISTÊMICA DO PORTFÓLIO BIBLIOGRÁFICO}

A partir dos artigos selecionados, foi realizada uma análise sistêmica, considerando as metodologias utilizadas para o desenvolvimento de cada proposta, sendo também listadas as contribuições disponibilizadas e percebidas de acordo com a análise, podendo ser observada na Tabela 3.

Tabela 3. Realização de análise sistêmica referente aos artigos selecionados presentes no banco.

\begin{tabular}{c|c|c|c}
\hline Artigo & Título & Metodologia/Técnica & Contribuição \\
\hline $\begin{array}{c}\text { Almeida et } \\
\text { al. (2020) }\end{array}$ & $\begin{array}{c}\text { Gestão dos fornecedores de } \\
\text { embalagens e uma empresa } \\
\text { de cosméticos }\end{array}$ & $\begin{array}{c}\text { Estudo de caso a partir de } \\
\text { entrevistas } \\
\text { semiestruturadas, Análise de } \\
\text { atividades e níveis de satisfação. }\end{array}$ & $\begin{array}{c}\text { Contribui com a análise do } \\
\text { relacionamento dos fornecedores do } \\
\text { tipontract manufacturer" e melhoria } \\
\text { do nível aquisitivo e gestão de } \\
\text { relacionamento com fornecedores. } \\
\text { Desta forma possibilitando } \\
\text { direcionamento no quesito tomada de } \\
\text { decisones operacionais. }\end{array}$ \\
\hline $\begin{array}{c}\text { Andrade e } \\
\text { Maria } \\
\text { (2015) }\end{array}$ & $\begin{array}{c}\text { Planejamento estratégico no } \\
\text { setor público: análise das } \\
\text { variáveis que influenciam o } \\
\text { processo de compras em } \\
\text { uma instituição de ensino }\end{array}$ & $\begin{array}{c}\text { Estudo de caso, onde através de } \\
\text { pesquisa } \\
\text { documental foram levantados dados } \\
\text { que posteriormente foram tratados } \\
\text { no Excel para análise dos } \\
\text { resultados. }\end{array}$ & $\begin{array}{c}\text { Contribui com a melhoria da dinâmica } \\
\text { do planejamento estratégico e } \\
\text { avaliadas as variáveis em uma planilha } \\
\text { direcionada demonstrando os que } \\
\text { mais impactaram na execução do } \\
\text { planejamento e nos itens de capital em } \\
\text { uma instituição de ensino pública. }\end{array}$ \\
\hline
\end{tabular}




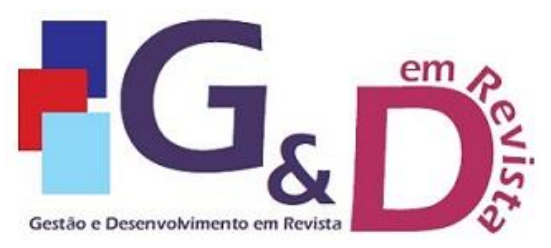

Gestão e Desenvolvimento em Revista

V. 7, N. 1, jan-jun/2021, p. 82-99.

ISSN online: $2446-8738$

Artigo recebido em: 05/06/2021

Artigo aprovado em: 16/08/2021

\begin{tabular}{|c|c|c|c|}
\hline $\begin{array}{l}\text { Aragão, } \\
\text { Holanda e } \\
\text { Kloeckner. } \\
(2020)\end{array}$ & $\begin{array}{l}\text { Estratégias no setor de } \\
\text { compras que influenciam a } \\
\text { performance das aquisições } \\
\text { de materiais indiretos em } \\
\text { uma empresa alimentícia }\end{array}$ & Curva ABC e a Matriz de Kraljic. & $\begin{array}{c}\text { Contribui com aplicação e } \\
\text { demonstração de metodologia no } \\
\text { processo de } \\
\text { aquisição, utilizando ferramentas que } \\
\text { auxiliam na formalização de } \\
\text { estratégias para a orientação na } \\
\text { efetivação de contratos. }\end{array}$ \\
\hline $\begin{array}{l}\text { Batalha e } \\
\text { Lima } \\
(2020)\end{array}$ & $\begin{array}{l}\text { Gestão de relacionamento } \\
\text { com fornecedores em uma } \\
\text { empresa do setor de bens de } \\
\text { consumo: um estudo de caso }\end{array}$ & $\begin{array}{l}\text { Modelos de seleção e contratação } \\
\text { de fornecedores, softwares de } \\
\text { supplier relationship management } \\
\text { (SRM). }\end{array}$ & $\begin{array}{l}\text { Auxilia na implementação e análise do } \\
\text { Software SEM (Gestão e } \\
\text { relacionamento com fornecedores) no } \\
\text { setor de compras, e aplicação de } \\
\text { modelo de seleção de fornecedores. }\end{array}$ \\
\hline $\begin{array}{l}\text { Bezerra et } \\
\text { al. }(2020) .\end{array}$ & $\begin{array}{c}\text { Proposta de metodologia } \\
\text { para avaliação e seleção de } \\
\text { fornecedores em uma } \\
\text { indústria madeireira: uma } \\
\text { abordagem baseada em } \\
\text { análise hierárquica de } \\
\text { processos }\end{array}$ & $\begin{array}{l}\text { Método de Análise Hierárquica de } \\
\text { Processos (AHP), utilizando dois } \\
\text { grupos de insumos como base e } \\
\text { análise multicritério de decisão. }\end{array}$ & $\begin{array}{l}\text { Contribui com a obtenção e seleção } \\
\text { dos indicadores mais importantes para } \\
\text { dar suporte à tomada de decisão e na } \\
\text { verificação da técnica utilizada sendo } \\
\text { adaptável ao departamento aplicado } \\
\text { possibilitando ajustes e modificações. }\end{array}$ \\
\hline $\begin{array}{l}\text { Bonato et } \\
\text { al. }(2019)\end{array}$ & $\begin{array}{c}\text { Iniciativas de } \\
\text { desenvolvimento de } \\
\text { fornecedores: estudo de caso } \\
\text { em uma indústria de } \\
\text { equipamentos de limpeza }\end{array}$ & Metodologia de pesquisa-ação & $\begin{array}{l}\text { O estudo de caso deste projeto utiliza } \\
\text { a pesquisa-ação e possibilita a } \\
\text { verificação na literatura de métodos e } \\
\text { cases de desenvolvimento de } \\
\text { fornecedores, identificada a melhor } \\
\text { ferramenta para ser utilizada. }\end{array}$ \\
\hline $\begin{array}{l}\text { Borba et al. } \\
\quad(2015)\end{array}$ & $\begin{array}{c}\text { Aplicação do sistema } \\
\text { máximo-mínimo no controle } \\
\text { de estoque de uma empresa } \\
\text { do segmento termoplástico }\end{array}$ & $\begin{array}{l}\text { Cálculos, análises e sistema de } \\
\text { conformidades. }\end{array}$ & $\begin{array}{l}\text { Contribui com aplicação do sistema } \\
\text { máximo-mínimo no controle de } \\
\text { estoques a partir do sistema de } \\
\text { demandas, assim auxiliando realizar } \\
\text { compras com exatidão evitando } \\
\text { rupturas e faltas de produtos em } \\
\text { estoque. }\end{array}$ \\
\hline $\begin{array}{l}\text { Carvalho e } \\
\text { Alves } \\
(2020)\end{array}$ & $\begin{array}{l}\text { Aplicação das ferramentas da } \\
\text { qualidade no setor de } \\
\text { compras visando redução de } \\
\text { custos }\end{array}$ & $\begin{array}{l}\text { Six Sigma, do DMAIC e do PDCA, } \\
\text { Brainstormings, Gráficos de Pareto, } \\
\text { 5W2H, PPAPs, Follow-Ups. }\end{array}$ & $\begin{array}{l}\text { Contribui com a aplicação das } \\
\text { ferramentas da qualidade na busca de } \\
\text { melhorias no setor de compras, } \\
\text { melhoria contínua, benefícios e } \\
\text { capacidades, garantindo } \\
\text { direcionamento em negociações e } \\
\text { decisões com a aplicação das } \\
\text { ferramentas. }\end{array}$ \\
\hline $\begin{array}{l}\text { Esteves et } \\
\text { al. (2020). }\end{array}$ & $\begin{array}{c}\text { Priorização de tipos de } \\
\text { compra por critérios } \\
\text { comerciais e aplicação de } \\
\text { AHP }\end{array}$ & $\begin{array}{l}\text { Analytic hierarchy process (AHP) na } \\
\text { priorização de tipos de compra. }\end{array}$ & $\begin{array}{c}\text { Contribui com a aplicação de uma } \\
\text { gestão eficaz no setor de compras, } \\
\text { impulsionando a melhoria aquisitiva e } \\
\text { análise de priorização dos tipos de } \\
\text { compras, cada produto possui seu } \\
\text { nível de giro, com isso alguns } \\
\text { necessitam de priorização na gestão } \\
\text { de compras. }\end{array}$ \\
\hline $\begin{array}{l}\text { Ganga et } \\
\text { al. (2016) }\end{array}$ & $\begin{array}{l}\text { Métodos quantitativos para } \\
\text { seleção de fornecedores } \\
\text { sustentáveis: uma revisão } \\
\text { sistemática da literatura }\end{array}$ & $\begin{array}{c}\text { Revisão sistemática da literatura, a } \\
\text { lógica fuzzy nas técnicas } \\
\text { multicritério, técnicas de análise de } \\
\text { conteúdo via tag } \\
\text { clouds e de análise de } \\
\text { correspondência. }\end{array}$ & $\begin{array}{l}\text { Auxilia na iniciativa de coletar, } \\
\text { identificar, selecionar e avaliar } \\
\text { criticamente os métodos quantitativos } \\
\text { utilizados na seleção de fornecedores } \\
\text { sustentáveis do ponto de vista verde e } \\
\text { social. }\end{array}$ \\
\hline $\begin{array}{l}\text { Machado, } \\
\text { Guimarães } \\
\text { e Lara } \\
(2020)\end{array}$ & $\begin{array}{l}\text { A importância das compras } \\
\text { de indiretos e suas } \\
\text { estratégias em uma empresa } \\
\text { de bens de consumo }\end{array}$ & $\begin{array}{c}\text { Estudo de caso, abordagem } \\
\text { qualitativa. }\end{array}$ & $\begin{array}{l}\text { Colabora no entendimento de melhoria } \\
\text { na rede de suprimentos, fazendo a } \\
\text { ligação direta com fornecedores, } \\
\text { transportadora, distribuidor, } \\
\text { revendedor e cliente final. } \\
\text { Impulsionando fatores relacionados a } \\
\text { melhoria de custos e aquisições. }\end{array}$ \\
\hline $\begin{array}{l}\text { Merces, } \\
\text { Pacheco e } \\
\text { Oliveira } \\
(2020)\end{array}$ & $\begin{array}{l}\text { O uso da curva abc para } \\
\text { gestão de estoques e } \\
\text { fornecedores: uma aplicação } \\
\text { em uma indústria de } \\
\text { compressores do interior de } \\
\text { São Paulo }\end{array}$ & Curva $A B C$ & $\begin{array}{c}\text { Contribui com avaliação da curva que } \\
\text { cada item e fornecedor se enquadram, } \\
\text { possibilitando traçar uma estratégia } \\
\text { e redução de custos. Cada item } \\
\text { possuindo sua classificação facilita no } \\
\text { momento de aplicação de forças e } \\
\text { estratégias sejam de compra ou } \\
\text { venda. }\end{array}$ \\
\hline
\end{tabular}




\begin{tabular}{|c|c|c|c|}
\hline $\begin{array}{l}\text { Moraes et } \\
\text { al. (2020). }\end{array}$ & $\begin{array}{l}\text { Cálculo e comparação de } \\
\text { modelos de previsão de } \\
\text { demanda de uma fabricante } \\
\text { de componentes plásticos }\end{array}$ & $\begin{array}{c}\text { Pesquisa Operacional, modelagem } \\
\text { matemática, cálculos dos erros de } \\
\text { previsão (MAE, RMSE e MAPE), } \\
\text { Aditivo de Winters. }\end{array}$ & $\begin{array}{c}\text { Contribui na procura de métodos para } \\
\text { previsão de demanda que tenha maior } \\
\text { acurácia e aprimorar o } \\
\text { planejamento de recursos. Utilizando a } \\
\text { pesquisa operacional com modelos } \\
\text { matemáticos, estatísticos buscando a } \\
\text { redução de desperdícios ou } \\
\text { superlotação de estoque e previsões. }\end{array}$ \\
\hline $\begin{array}{l}\text { Pimentel, } \\
\text { Cruz e } \\
\text { Guerreiro } \\
(2016)\end{array}$ & $\begin{array}{l}\text { Aplicação de técnicas de } \\
\text { previsão de demanda em } \\
\text { uma loja de materiais de } \\
\text { construção }\end{array}$ & $\begin{array}{c}\text { Média ponderada } \\
\text { para previsões de curto prazo, } \\
\text { 4MAD, }\end{array}$ & $\begin{array}{c}\text { Contribui com aprovação de } \\
\text { metodologias e mostra a importância } \\
\text { da previsão de demanda } \\
\text { para vendas futuras dos produtos da } \\
\text { empresa, a utilização da média } \\
\text { ponderada auxilia no entendimento e } \\
\text { aperfeiçoamento das previsões e } \\
\text { demandas direcionadas. } \\
\end{array}$ \\
\hline $\begin{array}{l}\text { Ronchi .et } \\
\text { al. (2016) }\end{array}$ & $\begin{array}{l}\text { Os reflexos da análise da } \\
\text { curva abc na gestão de } \\
\text { estoques de uma empresa } \\
\text { comercial de materiais de } \\
\text { construção }\end{array}$ & $\begin{array}{l}\text { Curva } A B C \text {, estoques máximos e } \\
\text { mínimos e a rotatividade do estoque. }\end{array}$ & $\begin{array}{l}\text { Analisa o estoque máximo utilizando } \\
\text { ferramentas disponíveis, auxilia na } \\
\text { redução do nível elevado de estoque } \\
\text { maximizando a rotatividade. } \\
\text { Possibilitando na classificação dos } \\
\text { produtos distribuindo forças no } \\
\text { momento de realizar ações e } \\
\text { aproveitamento nas compras. }\end{array}$ \\
\hline $\begin{array}{l}\text { Santos e } \\
\text { Silva } \\
(2020)\end{array}$ & $\begin{array}{c}\text { Aplicação do método de } \\
\text { previsão de demanda holt- } \\
\text { winters para uma empresa de } \\
\text { bebidas }\end{array}$ & $\begin{array}{c}\text { Holt-Winters, softwares Microsoft } \\
\text { Excel } \\
\text { e Minitab. }\end{array}$ & $\begin{array}{c}\text { Possibilita a visualização e } \\
\text { contribuição para resolução de } \\
\text { problemas com previsão de demanda. } \\
\text { A utilização de planilhas e holt-winters } \\
\text { funcionam como algoritmo, } \\
\text { direcionando a gestão e possibilitando } \\
\text { noções de demanda e necessidades } \\
\text { aquisitivas de forma organizada. }\end{array}$ \\
\hline $\begin{array}{l}\text { Saraiva, } \\
\text { Pereira e } \\
\text { Souza } \\
\text { (2015). }\end{array}$ & $\begin{array}{c}\text { Programação de suprimentos } \\
\text { e decisóes de compras: o } \\
\text { impacto em uma indústria } \\
\text { salineira }\end{array}$ & $\begin{array}{l}\text { Levantamento de dados, ERP, } \\
\text { programação de suprimentos. }\end{array}$ & $\begin{array}{l}\text { Contribui na melhoria da gestão dos } \\
\text { serviços desenvolvidos pelos setores } \\
\text { da empresa, financeiro e poder } \\
\text { aquisitivo. De certa forma, } \\
\text { programando a aquisição de } \\
\text { suprimentos com o ERP, facilita na } \\
\text { gestão e análise de dados, voltados a } \\
\text { indústria salineira. }\end{array}$ \\
\hline $\begin{array}{l}\text { Silva et al. } \\
\text { (2020). }\end{array}$ & $\begin{array}{c}\text { Gestão de estoque com a } \\
\text { implantação do sistema MRP } \\
\text { (planejamento de } \\
\text { requerimento de materiais) } \\
\text { em uma indústria de reatores }\end{array}$ & Sistema MRP de Planejamentos & $\begin{array}{l}\text { Contribui na aplicação do sistema } \\
\text { MRP com estoque de segurança, } \\
\text { disponibilidade e qualidade na } \\
\text { produção, redução do lead time do } \\
\text { ciclo produtivo. Calculando de forma } \\
\text { assertiva desde a aquisição da matéria } \\
\text { prima, os processos produtivos até o } \\
\text { produto acabado e entregue. }\end{array}$ \\
\hline $\begin{array}{l}\text { Toleto et al. } \\
\text { (2020). }\end{array}$ & $\begin{array}{l}\text { Proposta de aplicação da } \\
\text { teoria da utilidade para } \\
\text { tomada de decisão: escolha } \\
\text { do modal de importação em } \\
\text { um processo de compras } \\
\text { numa empresa do setor } \\
\text { tecnológico }\end{array}$ & Mapeamento de processo BPMN. & $\begin{array}{l}\text { Possibilita a visualização de tomada de } \\
\text { decisão e na definição de qual modal } \\
\text { de importação melhor se encaixa nas } \\
\text { situações. Mapeando os processos } \\
\text { facilita na detecção de falhas } \\
\text { reduzindo perdas, direcionando a } \\
\text { escolha de um modal de importação } \\
\text { adequado para a empresa listada. }\end{array}$ \\
\hline $\begin{array}{l}\text { Viana et al. } \\
\quad(2020)\end{array}$ & $\begin{array}{l}\text { Estudo comparativo entre } \\
\text { modelos de previsão de } \\
\text { demanda em uma empresa } \\
\text { de pronta entrega }\end{array}$ & $\begin{array}{l}\text { Abordagem quantitativa e } \\
\text { ferramentas de validação da } \\
\text { previsão de demanda. }\end{array}$ & $\begin{array}{l}\text { Contribui com o entendimento de } \\
\text { capacidade produtiva necessária em } \\
\text { cada período, auxilia na compra de } \\
\text { suprimentos e na promoção de uma } \\
\text { melhor administração dos estoques. } \\
\text { No caso da empresa a pronta entrega, } \\
\text { deve sempre ter produtos disponíveis, } \\
\text { evitando ao máximo rupturas, pois } \\
\text { trazer prejuízos a organização. }\end{array}$ \\
\hline
\end{tabular}

Fonte: Dos autores 


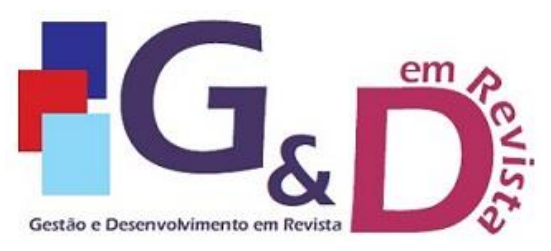

Gestão e Desenvolvimento em Revista V. 7, N. 1, jan-jun/2021, p. 82-99.

ISSN online: $2446-8738$

Artigo recebido em: 05/06/2021

Artigo aprovado em: 16/08/2021

\section{CONSIDERAÇÕES FINAIS}

De acordo com este artigo, conclui-se que ao fim do estudo, possibilita a partir da seleção de análise de projetos científicos publicados, agrupar informações importantes referentes à gestão estratégica no setor de compras. Com isso, a partir da metodologia utilizada, foi dada uma base para orientação e direcionamento, buscando a evolução da pesquisa científica e fortalecimento no estudo sob o tema abordado, condição proporcionada com a aplicação das técnicas de seleção e filtragem adequadas.

Destarte, os objetivos foram atingidos, em virtude de que foi apresentado o desenvolvimento e construção de uma base de artigos, um referencial teórico diretamente ligado ao tema pré-definido a partir da utilização da metodologia ProKnow-C, que permitiu a sistematização da atividade sendo objetiva e coerente perante a proposta. Ademais, essa sistematização auxiliou na organização e simplificação dos processos desenvolvidos, tendo como resultado a amplificação do conhecimento do pesquisador tendo saídas para justificativa do trajeto percorrido durante a pesquisa e seleção.

Assim, ao final da seleção e filtragem obteve-se um portfólio de 20 publicações com reconhecimento científico e alinhados ao que foi estabelecido. Inicialmente com a seleção de 1.402 artigos selecionados de periódicos, foram estabelecidos eixos e palavras-chave auxiliando na pesquisa e a partir da seleção, foram aplicados filtros e realizado análises buscando alcançar o sucesso deste resultado obtido, possibilitando o agrupamento de informações relevantes sobre o tema. Considerando que dentre os periódicos utilizados o Anais ENEGEP se destacou por ser o canal de publicações com maior volume entre os artigos selecionados.

Ter disponível este portfólio bibliográfico com as principais informações e artigos relevantes sobre um tema é fundamental para a criação de projetos e desenvolvimento de estudos que busque uma fonte segura que contenha informações consolidadas referentes ao assunto pesquisado. Com isso, vale acentuar a importância desta metodologia para obter publicações mais relevantes e atualizadas, autores em destaque, dentre outras informações. Com isso, notou-se também que a palavra-chave "Compras" se destacou entre os artigos selecionados, 
considerando artigos em português, estando presente em $75 \%$ deles, sendo tratada como evidência na busca de melhoria no setor.

O banco de artigos disponível nesse estudo pode auxiliar diretamente em pesquisas futuras de profissionais e partes interessadas no assunto proposto, dando espaço e direcionamento correto para novos projetos, disponibilizando publicações com reconhecimento científico de grande relevância.

\section{REFERÊNCIAS}

ALMEIDA, Vítor Meirelles dos Reis et al. Gestão dos fornecedores de embalagens e uma empresa de cosméticos. In: XL ENCONTRO NACIONAL DE ENGENHARIA DE PRODUÇÃO, 40, 2020, Foz do Iguaçu, PR. Anais... Foz do Iguaçu: ABEPRO, 2020.

ANDRADE, J. I. de; MARIA, R. C. Planejamento Estratégico no setor público: análise das variáveis que influenciam o processo de compras em uma instituição de ensino. In: XXXV ENCONTRO NACIONAL DE ENGENHARIA DE PRODUÇÃO, 35, 2015, Fortaleza, CE. Anais... Fortaleza: ABEPRO, 2015.

ARAGÃO, Lucas M. X.; HOLANDA, Thiago C.; KLOECKNER, Natalia V. R. Estratégias no setor de compras que influenciam a performance das aquisições de materiais indiretos em uma empresa alimentícia. In: XL ENCONTRO NACIONAL DE ENGENHARIA DE PRODUÇÃO, 40, 2020, Foz do Iguaçu, PR. Anais... Foz do Iguaçu: ABEPRO, 2020.

BAILY, P.; FARMER, D.; JESSOP, D.; JONES, D. Compras: Princípios e Administração. São Paulo: Atlas, 2000. 182p

BATALHA, Augusto A.; LIMA, Renato S. Gestão de relacionamento com fornecedores em uma empresa do setor de bens de consumo: um estudo de caso. In: XL ENCONTRO NACIONAL DE ENGENHARIA DE PRODUÇÃO, 40, 2020, Foz do Iguaçu, PR. Anais... Foz do Iguaçu: ABEPRO, 2020.

BEZERRA, Rodrigo Rangel Ribeiro et al. Proposta de metodologia para avaliação e seleção de fornecedores em uma indústria madeireira: Uma abordagem baseada em Análise Hierárquica de Processos. In: XL ENCONTRO NACIONAL DE ENGENHARIA DE PRODUÇÃO, 40, 2020, Foz do Iguaçu, PR. Anais... Foz do Iguaçu: ABEPRO, 2020.

.BONATO, Samuel Vinícius et al. Iniciativas de desenvolvimento de fornecedores: estudo de caso em uma indústria de equipamentos de limpeza. . In: XXVI SIMPÓSIO DE ENGENHARIA DE PRODUÇÃO, 26, 2019, Bauru, SP. Anais... Bauru: SIMPEP, 2019.

BORBA, Jeanderson Caique Ribeiro et al. Aplicação do sistema máximo-mínimo no controle de estoque de uma empresa do segmento termoplástico. In: XXXV ENCONTRO NACIONAL DE ENGENHARIA DE PRODUÇÃO, 35, 2015, Fortaleza, CE. Anais... Fortaleza: ABEPRO, 2015.

BOWESOX, Donald J. et al. Gestão Logística de Cadeia de Suprimentos. 1 ed. Bookman: Porto Alegre, 2006. 
CARVALHO, Guilherme B.; ALVES, Nelson A. Aplicação das Ferramentas da Qualidade no Setor de Compras Visando Redução de Custos. In: XL ENCONTRO NACIONAL DE ENGENHARIA DE PRODUÇÃO, 40, 2020, Foz do Iguaçu, PR. Anais... Foz do Iguaçu: ABEPRO, 2020.

CHIAVENATO, Idalberto. Administração da produção: uma abordagem introdutória. Rio de Janeiro: Elsevier, 2005.

CHIAVENATO, Idalberto. Administração nos Novos Tempos. 2. ed. Rio de Janeiro: Elsevier, 2004.

ESTEVES, Renato Figueira Guedes et al. Priorização de tipos de compra por critérios comerciais e aplicação de AHP. In: XXVII SIMPÓSIO DE ENGENHARIA DE PRODUÇÃO, 27, 2020, Bauru, SP. Anais... Bauru: SIMPEP, 2020.

GANGA, Gilberto Miller Devós et al. Métodos quantitativos para seleção de fornecedores sustentáveis: uma revisão sistemática da literatura. Revista Produção Online, v. 16, n. 4, p. 1434-1457, 2016.

GURGEL, F. A.; FRANCISCHINI, P. Administração de Materiais e do Patrimônio. São Paulo: Pioneira, 2002.

LUSTOSA, Leonardo J.; MESQUITA, Marco Aurélio de; QUELHAS, Osvaldo Luiz G.; OLIVEIRA, Rodrigo J. de. Planejamento e Controle da Produção. 2 ed. Rio de Janeiro: Elsevier, 2008.

MACHADO, Sofia L.; GUIMARÃES, Márcia R. N.; LARA, Felipe F. A importância das compras de indiretos e suas estratégias em uma empresa de bens de consumo. In: XXVII SIMPÓSIO DE ENGENHARIA DE PRODUÇÃO, 27, 2020, Bauru, SP. Anais... Bauru: SIMPEP, 2020.

MERCES, Renan M.; PACHECO, Bruna C. S.; OLIVEIRA, Layris M. O uso da curva abc para gestão de estoques e fornecedores: uma aplicação em uma indústria de compressores do interior de São Paulo. In: XL ENCONTRO NACIONAL DE ENGENHARIA DE PRODUÇÃO, 40, 2020, Foz do Iguaçu, PR. Anais... Foz do Iguaçu: ABEPRO, 2020.

MORAES, Nathalia Tessari et al. Cálculo e comparação de modelos de previsão de demanda de uma fabricante de componentes plásticos. In: XL ENCONTRO NACIONAL DE ENGENHARIA DE PRODUÇÃO, 40, 2020, Foz do Iguaçu, PR. Anais... Foz do Iguaçu: ABEPRO, 2020.

PIMENTEL, FQA; CRUZ, RGG; GUERREIRO, R. P. Aplicação de técnicas de previsão de demanda em uma loja de materiais de construção. In: XXXVI ENCONTRO NACIONAL DE ENGENHARIA DE PRODUÇÃO,36, 2016, João Pessoa PB. Anais... João Pessoa: ABEPRO, 2016.

RONCHI, L. M. et al. Os reflexos da análise da curva $A B C$ na gestão de estoques de uma empresa comercial de materiais de construção. In: XXXVI ENCONTRO NACIONAL DE ENGENHARIA DE PRODUÇÃO,36, 2016, João Pessoa PB. Anais... João Pessoa: ABEPRO, 2016.

SANTOS, Tharine da S.; SILVA, Liane M. F. Aplicação do método de previsão de demanda holt-winters para uma empresa de bebidas. In: XL ENCONTRO 
NACIONAL DE ENGENHARIA DE PRODUÇÃO, 40, 2020, Foz do Iguaçu, PR. Anais... Foz do Iguaçu: ABEPRO, 2020.

SARAIVA, Ana Clara Cachina; PEREIRA, José Raeudo; DE SOUSA, Juliana Araújo. Programação de suprimentos e decisões de compras: o impacto em uma indústria salineira. In: XXXV ENCONTRO NACIONAL DE ENGENHARIA DE PRODUÇÃO,35, 2015, Fortaleza, CE. Anais... Fortaleza: ABEPRO, 2015.

SILVA, Mariela Fioravanti da et al. Gestão de estoque com a implantação do sistema MRP (Planejamento de Requerimento de Materiais) em uma indústria de reatores. In: XL ENCONTRO NACIONAL DE ENGENHARIA DE PRODUÇÃO, 40, 2020, Foz do Iguaçu, PR. Anais... Foz do Iguaçu: ABEPRO, 2020.

SLACK, N.; CHAMBER, S.; HARDLAND, C.; HARRISON, A. e JOHNSTON, R. Administração da Produção. Ed. Atlas, São Paulo. 1999.

TELLES, Laís Silva.; LEAL, Ricardo. A gestão de compras em uma empresa do setor de comércio e serviços: utilizando o método do custo padrão na homologação de fornecedores. Revista Contexto, Porto Alegre, v .19, n. 41, p. 74 - 89, abr. 2019.

TOLEDO, Sandro Marcelo Muniz de et al. Proposta de Aplicação da Teoria da Utilidade para Tomada de Decisão: Escolha do Modal de Importação em um Processo de Compras numa Empresa do Setor Tecnológico. XL ENCONTRO NACIONAL DE ENGENHARIA DE PRODUÇÃO, 40, 2020, Foz do Iguaçu, PR. Anais... Foz do Iguaçu: ABEPRO, 2020.

VIANA, Danylo de Araújo et al. Estudo comparativo entre modelos de previsão de demanda em uma empresa de pronta entrega. XL ENCONTRO NACIONAL DE ENGENHARIA DE PRODUÇÃO, 40, 2020, Foz do Iguaçu, PR. Anais... Foz do Iguaçu: ABEPRO, 2020. 